\title{
Pleural Mesothelioma pT2 TNM Finding v7
}

National Cancer Institute

\section{Source}

National Cancer Institute. Pleural Mesothelioma pT 2 TNM Finding v7. NCI Thesaurus.

Code C88903.

Pleural mesothelioma with a tumor involving each of the ipsilateral pleural surfaces

(parietal, mediastinal, diaphragmatic, and visceral pleura) with at least one of the

following: involvement of diaphragmatic muscle; extension of tumor from visceral pleura into the underlying pulmonary parenchyma. (from AJCC 7th Ed.) 